\title{
Potential benefits of incentive spirometry following a rib fracture: a propensity score analysis
}

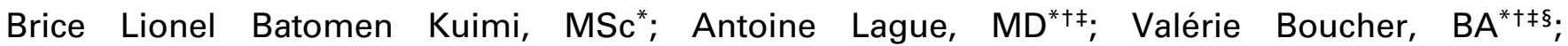 \\ Chantal Guimont, MD, PhD;; Jean-Marc Chauny, MD, MSc ${ }^{\top \| l}$; Jean-François Shields, MD; \\ Laurent Vanier, MD, $\mathrm{PhD}^{* *}$; Miville Plourde, $\mathrm{MD}, \mathrm{MSc}^{\ddagger}$; Marcel Émond, $\mathrm{MD}, \mathrm{MSc}^{*}+\S \uparrow$
}

\begin{abstract}
CLINICIAN'S CAPSULE
What is known about the topic?

Literature regarding the impact of incentive spirometry on patients with rib fractures is unclear; there are no recommendations for its use in the emergency department (ED). What did this study ask?

The objective of this study was to assess the impact of incentive spirometry on delayed complications in patients with rib fractures in the ED.

What did this study find?

Unsupervised incentive spirometry use does not have a protective effect against delayed pulmonary complications after a rib fracture.

Why does this study matter to clinicians?

Clear guidelines for incentive spirometry use for patients with rib fractures and further research to assess its usefulness in other ED populations are needed.
\end{abstract}

\section{ABSTRACT}

Objectives: Incentive Spirometry is commonly used for respiratory recovery. The literature on incentive spirometry and its impact on patients with rib fracture is unclear and there are no recommendations regarding its use in the Emergency Department (ED), particularly in rib fracture patients, which are known for increasing the risk of pulmonary complication. Therefore, the objective of this study was to assess the use of incentive spirometry and to measure its impacts on delayed complications in patients discharged from the ED with confirmed rib fracture.

Methods: This is a planned sub-study of a prospective observational cohort recruited in 4 Canadians ED between November 2006 and May 2012. Non-admitted patients over 16 y.o. with at least one confirmed rib fracture on radiographs were included. Prescription of incentive spirometry was left to attending physician. Main outcomes were development of pneumonia, atelectasis, and hemothorax within 14 days. Propensity score matching analyses were performed.

Results: 439 patients were included and 182 (41.5\%) patients received incentive spirometry. There were 99 cases of hemothorax $(22.6 \%), 103$ cases of atelectasis $(23.5 \%)$ and 4 cases of pneumonia $(0.9 \%)$. The use of incentive spirometry was not protector for hemothorax $[R R=1.03(0.66-1.64)]$ and atelectasis or pneumonia [RR $=1.07(0.68-1.72)]$.

Conclusions: Our results suggest that unsupervised incentive spirometry use does not have a protective effect against delayed pulmonary complications after rib fracture. Further research should be conducted to assess the usefulness of incentive spirometry in specific injured population in the ED.

\section{RÉSUMÉ}

Objectifs: La spirométrie incitative est parfois prescrite en vue d'encourager le rétablissement de la fonction respiratoire. Toutefois, peut de littérature est disponible sur la spirométrie incitative et ses effets chez les patients avec fracture de côtes, et il n'existe pas de recommandation sur son utilisation au département des urgences (DU), tout particulièrement pour les fractures de côtes, qui sont reconnues pour accroître le risque de complications pulmonaires. Cette étude visait donc à évaluer l'utilisation de la spirométrie incitative et à mesurer son impact sur l'incidence de complications tardives chez les patients ayant été libéré de l'urgence après une confirmation de fracture de côtes.

Méthode: II s'agit d'une sous-étude planifiée d'une étude observationnelle de cohorte prospective, qui a eu lieu dans 4 DU au Canada, entre novembre 2006 et mai 2012. Des patients âgés de 16 ans et plus, non hospitalisés, avec au moins une fracture de côte confirmée par radiographie ont été

From *Axe Santé des Populations et Pratiques optimales en santé, Centre de recherche du CHU de Québec - Université Laval, QC; †Centre de Recherche sur les Soins et Services de Première Ligne de I'Université Laval, QB; ¥Faculté de médecine, Université Laval, QB; §Centre d'Excellence sur le Vieillissement de Québec, QB; †Hôpital du Sacré-Cœur de Montréal, QB; ॥Département de médecine familiale et médecine d’urgence, Université de Montréal, QB; and ${ }^{*}$ Centre hospitalier de Charles-LeMoyne, Greenfield Park, QB.

Correspondence to: Dr. Marcel Émond, CHU de Québec - Université Laval, 1401, 18 ième rue, Québec, QB G1J 1Z4; Email: marcelemond1 @ me.com 
sélectionnés. La décision de prescrire la spirométrie incitative était laissée à la discrétion du médecin traitant. Les principaux résultats consistaient en l'apparition d'une pneumonie, d'atélectasie ou d'un hémothorax dans les 14 jours suivant le traumatisme. Des analyses d'appariement des coefficients de propension ont été réalisées.

Résultats: Un total de 439 patients ont participé à l'étude, dont $182(41,5 \%)$ ont été reçu la spirométrie incitative. 99 cas d'hémothorax $(22,6 \%), 103$ cas d'atélectasie $(23,5 \%)$ et 4 cas de pneumonie $(0,9 \%)$ ont été observés. Nos résultats indiquent que la spirométrie incitative ne semble pas un moyen de protection contre I'hémothorax (risque relatif $[R R]=1,03$
$[0,66-1,64])$ ni contre l'atélectasie ou la pneumonie $(\mathrm{RR}=1,07$ [0,68-1,72]).

Conclusion: Nos résultats suggèrent que la spirométrie incitative non supervisée $n^{\prime}$ offrirait pas d'effet protecteur contre I'apparition tardive de complications pulmonaires à la suite d'une fracture de côtes. D'autres recherches sont nécessaires afin de valider la pertinence de prescrire la spirométrie incitative au DU, chez certains groupes de blessés plus spécifiques.

Keywords: Emergency department, incentive spirometry, rib fracture

\section{INTRODUCTION}

Incentive spirometry is commonly used after surgery to maximize lung inflation. ${ }^{1}$ Full lung expansion and decreased pleural pressure are known to prevent fluid build-up and complications such as atelectasis and pneumonia. $^{1,2}$

There are currently no recommendations regarding incentive spirometry use in patients with a rib fracture in the emergency department (ED). Chest injuries are a common complaint in the $\mathrm{ED},{ }^{3}$ and $75 \%$ of $\mathrm{ED}$ patients consulting for a minor thoracic injury (with or without a rib fracture) are not hospitalized. However, the risk of pulmonary complications increases with the number of rib fractures, ${ }^{4}$ and patient management and admission/discharge follow-up plans are highly heterogeneous. ${ }^{5}$ Clear recommendations should be made for incentive spirometry use in patients with a rib fracture consulting to the ED.

The objective of this study was, therefore, to evaluate the impact of incentive spirometry use in patients with a rib fracture discharged from the ED.

\section{METHODS}

\section{Setting}

This is a planned sub-analysis of a multicentre prospective cohort study. ${ }^{6}$ Patients were included if they 1 ) were $\geq 16$ years old; 2 ) presented to a participating $E D$ with at least one confirmed rib fracture on radiographs between 2006 and 2012; and 3) were discharged from the ED. An incentive spirometry prescription was left to the discretion of the attending physician. Participants received a five-minute teaching session by the ED nurse before discharge. Follow-up was conducted 7 and 14 days after the ED visit, with standard upright chest radiographs to ascertain potential delayed complications.

\section{Outcomes}

Three main delayed complications were assessed: hemothorax (any new pleural fluid collection), atelectasis (based on blinded radiologist reports), and pneumonia (according to the medical follow-up done by a physician) within 14 days of the $\mathrm{ED}$ visit. Because of the lower number of pneumonia cases, they were combined with atelectasis.

\section{Statistical analysis}

As the decision to prescribe incentive spirometry highly depends on a patient's clinical presentation, matching by propensity score was used to ensure a balance of covariates between the groups (incentive spirometry v. no incentive spirometry). ${ }^{7}$ Propensity scores were estimated using a logistic regression. We performed 1:1 matching based on logit of propensity scores. ${ }^{8}$ Matched analyses estimate the average treatment effect on the treated. The standardized difference (SD) was used to check the balance of covariates between matched and unmatched. ${ }^{8}$ Bootstrapping was used to estimate the confidence intervals (CI). All analyses were performed using SAS 9.4. ${ }^{9}$

\section{Statistical Power}

A propensity score match is a good alternative when adjusting for potential confounders is impossible with 
traditional conditional methods. Anticipating that about $30 \%$ of patients on IS would not be matched, we estimated a power of $80 \%$ (alpha of 0.05 ) to detect any relative risks outside the $(0.6$ and 1.67$)$ interval. ${ }^{10,11}$

\section{RESULTS}

The initial cohort for the main study included a total of 1,474 patients. $^{6}$ Of those, patients without a confirmed rib fracture (997), patients on warfarin (11), and patients lost to follow-up (27) were excluded, leaving a sample of 439 patients. Incentive spirometry was prescribed to $41.5 \%$ of these patients at ED discharge. Predictors of incentive spirometry administration include initial saturation, opiates, and number of rib fractures (Table 1 Supplemental files). There were $99(22.6 \%)$ cases of hemothorax (53 with incentive spirometry), 103 $(23.5 \%)$ cases of atelectasis (49 with incentive spirometry), and 4 cases of pneumonia $(0.9 \%)$ within the 14-day follow-up period.

Crude analyses reported a relative risk (RR) between incentive spirometry and hemothorax of 1.63 (95\% CI 1.15-2.3) and 1.29 (95\% CI 0.93-1.79) for atelectasis/ pneumonia (Table 2).

Figures 1, 2, and 3 (Supplemental files) show the propensity score matching results. Balance of almost all covariates was achieved $(\mathrm{SD}<0.1)$.

The RR of the matched sample was 1.03 (95\% CI 0.66-1.61) for hemothorax and 1.07 (95\% CI 0.681.72) for atelectasis or pneumonia (Table 2). Similar results were obtained, while adjusting for covariates with a standardized mean difference $>0.1$ (sex, trauma mechanism, and respiration rate); RR of 0.98 (95\% CI 0.62-1.55) was determined for delayed hemothorax, and RR of 1.15 (95\% CI $0.71-1.85$ ) was demonstrated for delayed atelectasis or pneumonia.

\section{DISCUSSION}

Our results suggest that unsupervised incentive spirometry does not prevent delayed atelectasis, pneumonia, or delayed hemothorax within 14 days of an ED visit for a rib fracture. However, our 95\% CIs were large and contained the null value, leading to similar results demonstrated by Tyson et al., ${ }^{12}$ who concluded that the use of unmonitored incentive spirometry after laparotomy did not demonstrate a significant improvement in pulmonary function.

Medical literature is not clear on the effect incentive spirometry on postoperative pulmonary complications (PPC). A 2001 systematic review showed no evidence supporting incentive spirometry use to decrease the incidence of PPC following cardiac or upper abdominal surgery. ${ }^{13}$ However, incentive spirometry was shown to reduce the incidence of PPC after coronary artery bypass grafts or major abdominal surgery. ${ }^{14,15} \mathrm{~A}$ more recent systematic review concluded that incentive spirometry has positive effects on preventing PPC. ${ }^{16}$ Literature regarding incentive spirometry use in patients who sustained minor thoracic trauma is sparse, and current evidence concludes that the decision to use incentive spirometry following thoracic surgery should be made by physiotherapists. ${ }^{17}$ To our knowledge, there is no specific study regarding incentive spirometry use in the $\mathrm{ED}$, and, therefore, its use is based on surgical guidelines. Our findings suggest that unsupervised incentive spirometry does not impact the incidence of delayed complications in patients who are discharged with a rib fracture.

The absence of unmeasured confounders is one of the key assumptions while using propensity scores to estimate causal effects. ${ }^{11}$ Therefore, if incentive spirometry assignment to patients is based on clinical judgment, controlling for prognostic factors alone in our propensity model leaves residual confounding by indication. ${ }^{18}$ Age and a higher complication risk are confounding factors that could have influenced the medical decision to offer incentive spirometry. However, the majority of patients $(75 \%)$ in the matched population were under the age of 65 years. Because of the limited number of seniors, further statistical analyses were not possible.

Patient adherence to the incentive spirometry treatment was not monitored that may have skewed results. Furthermore, chest X-rays were used to diagnose pulmonary complications. A new pleural effusion was considered a hemothorax, so the incidence of this complication may have been overestimated. Finally, 59 $(32 \%)$ patients who used incentive spirometry were not matched, limiting the generalization of our findings.

\section{CONCLUSION}

To our knowledge, this study was the first to assess the use of unsupervised incentive spirometry for patients 
with a rib fracture in the ED. Our results were similar to those obtained in postoperative care studies. There was no decrease in post-discharge complications (pneumonia, atelectasis, and hemothorax) for rib fractures in patients who used incentive spirometry. A randomized control study should be done to assess the use of supervised incentive spirometry specifically in seniors or patients at high risk of delayed complications who are discharged from the ED.

Acknowledgements: We are grateful to all Emergency Physicians and research assistants at our participating centres who recruited and followed our study participants.

Competing interests: This work was supported by a grant from Fonds de la Recherche en Santé du Québec (FRSQ 14056).

\section{SUPPLEMENTARY MATERIAL}

The supplementary material for this article can be found at https://doi.org/10.1017/cem.2018.492.

\section{REFERENCES}

1. Brunner LS, Smeltzer SC, Bare BG, Hinkle JL, Cheever KH. Brunner \& Suddarth's textbook of medical-surgical nursing. Wolters Kluwer Health/Lippincott Williams \& Wilkins; 2010.

2. Branson RD. The scientific basis for postoperative respiratory care. Respir Care 2013;58(11):1974-84.

3. Rui P, Kang K. National Hospital Ambulatory Medical Care Survey: 2014 Emergency Department Summary Tables. Centers for Disease Control and Prevention, Statistics NCfH; 2014. Available at: https://www.cdc.gov/nchs/ data/nhamcs/web_tables/2014_ed_web_tables.pdf (accessed January 1, 2019).

4. Chien CY, Chen YH, Han ST, et al. The number of displaced rib fractures is more predictive for complications in chest trauma patients. Scand 7 Trauma Resusc Emerg Med 2017;25(1):19.

5. Shields JF, Emond M, Guimont C, Pigeon D. Acute minor thoracic injuries: evaluation of practice and follow-up in the emergency department. Can Fam Physician 2010;56(3): e117-24.

6. Émond M, Guimont C, Chauny JM, et al. Clinical prediction rule for delayed hemothorax after minor thoracic injury: a multicentre derivation and validation study. CMAf Open 2017;5(2):E444-53.

7. Williamson E, Morley R, Lucas A, Carpenter J. Propensity scores: from naive enthusiasm to intuitive understanding. Stat Methods Med Res 2012;21(3):273-93.

8. Austin PC. An introduction to propensity score methods for reducing the effects of confounding in observational studies. Multivariate Behav Res 2011;46(3):399-424.

9. Coca-Perraillon M, ed. Local and global optimal propensity score matching. SAS Global Forum; 2007.

10. Brookhart MA, Schneeweiss S, Rothman KJ, et al. Variable selection for propensity score models. Am 7 Epidemiol 2006;163(12):1149-56.

11. Stuart EA. Matching methods for causal inference: a review and a look forward. Stat Sci 2010;25(1):1-21.

12. Tyson AF, Kendig CE, Mabedi C, Cairns BA, Charles AG. The effect of incentive spirometry on postoperative pulmonary function following laparotomy: a randomized clinical trial. FAMA Surg 2015;150(3):229-36.

13. Overend TJ, Anderson CM, Lucy SD, et al. The effect of incentive spirometry on postoperative pulmonary complications: a systematic review. Chest 2001;120(3):971-8.

14. Haeffener MP, Ferreira GM, Barreto SSM, Arena R, Dall'Ago P. Incentive spirometry with expiratory positive airway pressure reduces pulmonary complications, improves pulmonary function and 6-minute walk distance in patients undergoing coronary artery bypass graft surgery. Am Heart Z 2008;156(5):900.e1-.e8.

15. Westwood K, Griffin M, Roberts K, et al. Incentive spirometry decreases respiratory complications following major abdominal surgery. Surgeon 2007;5(6):339-42.

16. Rupp M, Miley H, Russell-Babin K. Incentive spirometry in postoperative abdominal/thoracic surgery patients. $A A C N$ Adv Crit Care 2013;24(3):255-63.

17. Agostini $P$, Singh S. Incentive spirometry following thoracic surgery: what should we be doing? Physiotherapy 2009;95 (2):76-82.

18. Bosco JL, Silliman RA, Thwin SS, et al. A most stubborn bias: no adjustment method fully resolves confounding by indication in observational studies. 7 Clin Epidemiol 2010;63(1):64-74. 